\title{
Esquema básico de metadados para representação descritiva de obras de arte em museus brasileiros
}

\author{
Basic metadata scheme for the descriptive representation \\ of works of art in Brazilian museums
}

\author{
Camila Aparecida da SILVA' (iD) 0000-0003-3568-592X \\ Marilda Lopes Ginez de LARA' 1 (D) 0000-0003-1906-8606
}

\section{Resumo}

Este trabalho tem como objetivo analisar recomendações de diretrizes internacionais sobre a representação descritiva de objetos museológicos e, a partir delas, propor um esquema básico de metadados para representar obras de arte, considerando os contextos brasileiros. A proposta se justifica uma vez que parte dos museus locais declaradamente afirma não registrar suas coleções e que outra parte não adota recursos metodológicos para a catalogação. A metodologia utilizada teve apoio na literatura de terminologia, para o cotejo de metadados, bem como na norma de construção de tesauros da International Standard Organization no 25964-1/2 e na literatura internacional, para a realização do mapeamento e do crosswalk das diretrizes selecionadas. Como resultado, foi elaborado um esquema concreto de metadados para orientar metodologicamente a descrição básica de coleções de arte, e foram feitas sugestões sobre sua utilização por museus de arte em nível nacional. A aplicabilidade do esquema foi verificada a partir de uma pequena amostra que buscou representar a diversidade das categorias da tipologia Artes Visuais presentes nos museus do Brasil. Acredita-se que a adoção de um esquema mínimo de metadados nas práticas catalográficas dos museus brasileiros poderá contribuir para uma maior organização das informações sobre as obras e permitir sua recuperação de modo mais consistente, potencializando o acesso às informações sobre essas coleções de arte no cenário nacional e internacional. A reflexão sobre o emprego de metodologias para o tratamento informacional das obras de museus põe em destaque a necessidade emergencial do uso de processos, de procedimentos e de políticas de gestão de coleções museológicas alinhados entre si, em função do desenvolvimento de boas práticas. Como continuidade do trabalho, está projetada a expansão do experimento para análise e para identificação de situações não previstas no uso da proposta.

Palavras-chave: Catalogação. Metadados. Museus de arte. Representação da informação. Representação descritiva.

\begin{abstract}
This paper examined international guidelines for the descriptive representation of museum objects to propose, based on such guidelines, a basic metadata scheme to represent artworks considering the Brazilian scenario. This proposal is justified, since part of local museums
\end{abstract}

\footnotetext{
1 Universidade de São Paulo, Escola de Comunicações e Artes, Programa de Pós-Graduação em Ciência da Informação. Av. Prof. Lúcio Martins Rodrigues, 443, Cidade Universitária, 05508-020, São Paulo, SP, Brasil. Correspondência para/Correspondence to: M. L. G. LARA. E-mail: <larama@usp.br>.

Artigo elaborado a partir da tese de C.A. SILVA, intitulada "Esquema de metadados para descrição de obras de arte em museus brasileiros: uma proposta". Universidade de São Paulo, 2020.

Apoio/Support: Coordenação de Aperfeiçoamento de Pessoal de Nível Superior (Código de Financiamento 001) e Conselho Nacional de Desenvolvimento Científico e Tecnológico.

Recebido em 27 de julho de 2020, reapresentado em 19 de outubro de 2020 e aprovado em 2 de dezembro de 2020.

Como citar este artigo/How to cite this article

Silva, C. A.; Lara, M. L. G. Esquema básico de metadados para representação descritiva de obras de arte em museus brasileiros. Transinformação, v. 33 , e200050, 2021. https://doi.org/10.1590/2318-0889202133e200050
} 
clearly stated that they are not cataloguing their collections and another part does not adopt standardized resources for that activity. The methodology applied in this research was based on: a) the Terminology literature, used to compare and to analyze metadata, and b) the International Standard Organization no 25964-1/2 as well as on the international literature, used to perform a mapping and a crosswalk of the selected guidelines in this investigation. As a result, a concrete metadata scheme was developed as a methodological guide for the basic descriptive representation of artwork collections in Brazil; in addition, suggestions were made for its implementation in the national scenario. The application of such scheme was tested and validated using a small sample of artworks that sought to include different categories of this type of work available in Brazilian museums. It is believed that the implementation of a minimum metadata scheme in the cataloguing activity of Brazilian museums may enhance the information organization of artworks and contribute to the consistency of information retrieval. Moreover, it may maximize the access to the information of artwork collections located in Brazil for national and international audiences. The analysis of international guidelines for the information representation of museum objects draws attention to an urgent necessity of using processes, procedures, and collection management policies. For this purpose, these fundamental components must be aligned to promote best practices. A future experimental investigation should include more types of artworks in the sample to verify different implementations of the basic metadata schemes proposed as well as to observe and to identify conditions and attributes not predicted in the use of the proposal.

Keywords: Cataloguing. Metadata. Art museums. Information representation. Descriptive representation.

\section{Introdução}

Este artigo trata de recursos metodológicos de representação descritiva voltados para obras de arte, tendo em vista o panorama de carência de registro catalográfico constatado em parte significativa dos museus brasileiros, conforme mostram os dados do Cadastro Nacional de Museus (Instituto Brasileiro de Museus, 2010)² e as reflexões de Monteiro (2014) e de Panisset (2017a). Buscou-se analisar diretrizes específicas para acervos museológicos e, a partir delas, desenhar um esquema básico e mínimo de metadados que possa auxiliar museus brasileiros na catalogação de seus acervos. Catalogação e representação descritiva são usadas, neste texto, como sinônimos.

As diretrizes selecionadas para a construção de um esquema básico de metadados foram a Standard Procedures for Collections Recording Used in Museums (SPECTRUM), da Collections Trust; as Categorias de informação, do Comitê Internacional para Documentação (CIDOC) do Conselho Internacional de Museus (ICOM); e a Categories for the Description of Works of Art (CDWA), do Getty Research Institute. A metodologia aplicada para a sua análise e o consequente desenho do esquema básico de metadados teve apoio na literatura de Terminologia apresentada por Barros (2004) e por Krieger e Finatto (2018), que cobre o uso de fichas de coleta e síntese terminográficas, bem como na norma no 25964-1/2 da International Organization for Standardization (ISO) (International Organization for Standardization, 2011a; 2011b) e em Woodley (2016), que abrangem os recursos de mapeamento e de crosswalk, necessários para o cotejo dos componentes de cada diretriz.

Embora a metodologia apresentada na norma no 25964-2 (International Organization for Standardization, 2011b) seja destinada especificamente ao mapeamento de tesauros, utilizados para representação temática, essa metodologia serviu como referência para o mapeamento das três diretrizes museológicas de representação descritiva selecionadas para este trabalho, de modo a contribuir para a elaboração do esquema de metadados para obras de arte.

A análise das diretrizes em foco resultou em um produto documentário prático e flexível, composto por designações e por definições específicas para cada metadado básico selecionado. Esse produto poderá ser utilizado como um modelo de referência pelos museus brasileiros com acervos de Artes Visuais, uma vez que é passível de ajustes ao perfil das coleções e às necessidades de cada instituição museológica.

Primeiramente, serão apresentados o estado da arte da catalogação nos acervos museológicos no Brasil e os instrumentos de referência para a catalogação de obras de arte em acervos museológicos. Em seguida, serão apontadas as condições para a elaboração de um esquema básico e sintético de metadados para a representação

\footnotetext{
2 Dados fornecidos pelo Instituto Brasileiro de Museus (IBRAM) em 24 ago. 2018 por solicitação via Sistema Eletrônico do Serviço de Informação ao Cidadão, conforme a Lei no 12.527/2011 (Lei de Acesso à Informação [LAI]).
} 
descritiva de obras de arte no contexto brasileiro, fundamentadas principalmente na Collections Trust (2014), em Gilliland (2016) e em Baca (2016a; 2016b). Na sequência, serão verificadas as etapas para o cotejo das diretrizes e para a análise dos formatos de descrição recomendados, o que culminará na apresentação da proposta, juntamente com a sua aplicação em uma amostra coletada de museus distribuídos no Brasil. As discussões sobre o experimento foram amparadas em Buck (2010), em Young (2010) e em Panisset (2017b), e as discussões dos resultados gerais em Lara (2013), Baca (2016b) e Harpring (2019). Incluem, ainda, breves indicações sobre aplicações da proposta em suportes de registro para o ambiente digital, como o Tainacan. As considerações finais indicam os prováveis benefícios e os desdobramentos do esquema básico de metadados proposto.

\section{O estado da arte da catalogação nos acervos museológicos no Brasil}

Objetos museológicos classificados na tipologia Artes Visuais compõem os acervos exclusivos de arte, ou seja, os museus de arte. Já os acervos com mais de uma tipologia, aqui nomeados 'museus mistos' ou 'híbridos', podem englobar, além de Artes Visuais, bens culturais de Antropologia e Etnografia, de Arqueologia, de Ciências Naturais e História Natural, de Ciência e Tecnologia, de História, de Imagem e Som, Virtual, Biblioteconômico, Documental e Arquivístico segundo as tipologias adotadas pelo IBRAM (Instituto Brasileiro de Museus, 2011).

De acordo com os dados do Cadastro Nacional de Museus (CNM), disponibilizados pelo IBRAM e tabulados para esta pesquisa, há no Brasil 677 'museus mistos' e 99 museus de arte (Instituto Brasileiro de Museus, 2010). No primeiro grupo, 133 museus declararam no CNM não registrar seus acervos em nenhum dos instrumentos de registro considerados pelo Cadastro, contra 11 museus do segundo grupo, o que revela parte do problema deste trabalho: 144 museus com coleções de arte não catalogaram seus bens culturais pelo menos até 2010.

Para a classificação das informações sobre museus, o CNM solicita dados sobre o que considera serem instrumentos de registro: a Documentação fotográfica, a Ficha de catalogação/registro, o Livro de registro e o Software/Programa informatizado, que são, na verdade, suportes de registro. Não há perguntas sobre os recursos utilizados para o registro informacional dos acervos, o que implica a ausência de dados sobre formas de catalogação. Esse diagnóstico impreciso, somado aos relatos e aos estudos de caso apresentados em eventos, mostra que uma parcela dos museus brasileiros com acervos de Artes Visuais não dispõe de instrumentos para o registro catalográfico de suas obras, por não conhecerem diretrizes destinadas a esse fim ou por não saberem como utilizá-las. Outras possíveis causas são a insuficiência de recursos financeiros e/ou estruturais, de recursos humanos, de capacitação e de investimentos em formação, de treinamentos, de tempo e mesmo de vontade, em alguns casos. A existência de museus brasileiros que não adotam recursos metodológicos para a representação descritiva em nível básico de seus acervos artísticos implica o não processamento das informações e, consequentemente, a desorganização de uma massa informacional e documental que, de outra forma, permitiria uma maior visibilidade das coleções artísticas nacionais. Por sua vez, essa ausência de informações registradas tem como efeito a ineficiência de serviços de informação a curadores, a pesquisadores e ao público em geral.

No cenário nacional, o levantamento de orientações para a descrição de objetos museológicos mostra poucas publicações amplamente conhecidas sobre o assunto. Dentre elas, destacam-se: os livros "Introdução à Técnica de Museus", de Barroso (1946), e "O museu ideal", de Real (1958); o manual "Museus, aquisição/ documentação: tecnologias apropriadas para a preservação dos bens culturais", de Camargo-Moro (1986); e o "Manual de catalogação de pinturas, esculturas, desenhos e gravuras", do Museu Nacional de Belas Artes do Rio de Janeiro (MNBA-RJ), produzido por Ferrez e Peixoto (1995). Este último, com orientações para o uso do sistema Donato, criado no MNBA-RJ e distribuído gratuitamente para museus brasileiros que manifestassem interesse, com licença cedida até 2012. Segundo Monteiro (2014, p.68), esses materiais foram listados entre as "poucas referências publicadas no Brasil sobre parâmetros de descrição física de tipologias específicas de acervo". Observa-se, também, com exceção do Manual do MNBA-RJ, que essas obras bibliográficas, publicadas entre 1940 e 1990, não são destinadas a uma tipologia específica de acervo museológico. 


\section{Instrumentos de referência para a catalogação de obras de arte em acervos museológicos}

A situação anteriormente referida pode ser alterada, considerando-se a existência de diretrizes atuais, reconhecidas internacionalmente e destinadas a objetos museológicos. Para se compreender a amplitude e a aplicabilidade desses instrumentos para a descrição de coleções artísticas no contexto brasileiro, foram selecionadas três diretrizes para análise: (1) a SPECTRUM, da Collections Trust sediada no Reino Unido; (2) as Categorias de Informação do CIDOC-ICOM, órgão associado à Organização das Nações Unidas para a Educação, a Ciência e a Cultura e (3) a CDWA, elaborada pelo Getty Research Institute, dos Estados Unidos.

A SPECTRUM é uma diretriz composta por um conjunto de procedimentos que visa à gestão de coleções museológicas e que inclui o Procedimento de catalogação, o qual será objeto de análise detalhada neste trabalho. Ela foi publicada pela primeira vez em 1994 e, desde então, tem passado por atualizações. A segunda diretriz selecionada foi criada em 1995 e, apesar de não ter sofrido alterações, é produto do órgão de maior representatividade no setor de documentação em museus, o CIDOC-ICOM. As duas diretrizes não são voltadas para tipologias específicas, isto é, buscam abranger todo tipo de objeto museológico, e ambas foram traduzidas para o português do Brasil e lançadas em 2014 dentro da série denominada "Coleção gestão e documentação de acervos: textos de referência" (Secretaria de Estado da Cultura de São Paulo, 2014), por iniciativa da Secretaria de Cultura do Estado de São Paulo (SEC-SP), em parceria com instituições locais. A referida série é voltada à comunidade profissional falante da língua portuguesa e tem como objetivo a publicação de materiais considerados relevantes para o setor museológico. As publicações da série podem ser vistas como uma tentativa de chamar a atenção para a urgência, em nível nacional, de estabelecimento de práticas documentárias apoiadas em princípios e em padrões, conforme anunciado por Panisset (2017a, p.300):

\footnotetext{
A consciência crítica no Brasil sobre as ferramentas, as metodologias e a teoria sobre o tratamento da informação artística não está ainda consolidada, quer no campo museológico, da documentação e da arquivologia, quer na área de história, teoria e crítica da arte, quer na esfera da conservação e até mesmo em relação aos produtores de arte e sistemas de comunicação. Tal situação reforça a demanda de formalização de paradigmas respaldados na Ciência da Informação, bem como a constituição de um debate colaborativo - não hierárquico, excludente ou de autoridade epistemológica - entre as áreas do conhecimento.
}

Para efeito deste trabalho, utilizou-se a versão da SPECTRUM 4.0 traduzida para o português do Brasil. Atualmente, essa diretriz encontra-se na versão 5.0 (Collections Trust, 2017), porém sua atualização ainda não está disponível em português.

Os títulos originais das diretrizes são, respectivamente, "SPECTRUM 4.0: the UK museum collections management standard" (Collections Trust, 2011) e "International guidelines for museum object information: the CIDOC information categories" (CIDOC-ICOM, 1995). Também foram objeto de tradução para o Português Brasileiro, por iniciativa da iniciativa da SEC-SP, os princípios gerais estabelecidos pelo CIDOC-ICOM que objetivam nortear a documentação em museus, originalmente intitulada "Statement of principles of museum documentation" (CIDOC-ICOM, 2012). Essa última recomendação buscou cobrir uma lacuna da publicada em 1995, mais voltada ao fornecimento de elementos práticos para o registro de objetos museológicos do que aos princípios gerais de documentação.

Já a CDWA, terceira diretriz selecionada para análise, diferente das anteriores, é destinada a obras de arte. Criada em meados dos anos 1990, é atualizada regularmente e disponibilizada eletronicamente somente em inglês. Dentre as diretrizes sob análise, é a mais detalhada em suas orientações. 


\section{As condições para a elaboração de um modelo básico de metadados para a representação descritiva das obras de arte no contexto brasileiro}

A análise efetuada parte da hipótese de que as diretrizes acima citadas constituem uma referência importante e fundamental para a descrição de objetos museológicos. Considera, contudo, que é possível elaborar um esquema básico mais sintético que reúna os principais metadados para a representação das informações sobre as coleções de arte, levando em conta a precariedade de grande parte dos museus de arte brasileiros em termos de recursos financeiros e humanos. A elaboração do esquema compreendeu desde o exercício para a apreensão dos conceitos presentes nas obras de referência selecionadas, passando pela seleção do que se pode julgar essencial e importante para a representação das obras de arte, até a verificação da aplicabilidade do esquema básico proposto, realizada a partir de um teste em um grupo selecionado de obras de arte representativas das coleções locais nacionais.

Um esquema de metadados mínimos pode ser considerado um tipo de padrão de estrutura de dados (Gilliland, 2016). Ele é composto por um conjunto básico de categorias utilizadas para representar informações sobre documentos que, no caso deste trabalho, são as obras de arte. A implantação de um esquema de metadados confere consistência às informações sobre objetos museológicos e estimula a padronização de registros.

A consistência de informações e a padronização de registros poderão ser alcançadas com o uso de um padrão de estrutura de dados aliado à utilização de padrões de valor (vocabulários controlados) e de conteúdo de dados (regras de catalogação), que contribuem para a recuperação e para o acesso informacional sobre os bens culturais.

Em especial, o uso de um esquema de metadados faz com que o capital intelectual sobre um acervo não seja perdido, independentemente do suporte utilizado, seja manual ou digital (Baca, 2016a; Gilliland, 2016). Em outras palavras, as informações processadas sobre um objeto estarão preservadas dentro de um formato de descrição sistematizado e poderão ser transferidas para outros suportes sem prejuízo de sua estrutura.

Esse esquema deve ser acompanhado por um manual de catalogação com as decisões e os critérios definidos no dia a dia da instituição. Documentar por escrito cada passo para a realização de uma atividade é, de acordo com a Collections Trust (2014), essencial para a manutenção de procedimentos, pois informa e conscientiza a equipe do museu sobre as práticas adotadas. A documentação dos procedimentos também garante sua permanência ao longo do tempo, de modo que as próximas gerações de funcionários poderão entender a lógica dos processos de registro. Evidentemente, revisões regulares deverão ser realizadas.

Seguindo esse raciocínio, o estabelecimento de um esquema de metadados devefazer parte do procedimento de catalogação que, por sua vez, deve estar previsto na política de documentação do museu, elaborada em harmonia com a sua missão e com os seus objetivos. Juntas, as políticas de aquisição, de acesso, de conservação e de documentação formam a política de gestão de coleções museológica (Collections Trust, 2014). De acordo com Simmons (2010), a implantação de políticas desse tipo representa o compromisso do museu com boas práticas profissionais. De modo geral, infelizmente, as políticas institucionais desse gênero não são uma realidade em parte significativa dos museus do Brasil. Mais informações sobre política de gestão de coleções podem ser encontradas na Publicly Available Specification denominada PAS-197:2009, publicada pela British Standards Institution (2009), em Simmons (2010) e em Paaskoski et al. (2014).

Os museus brasileiros necessitam definir processos, procedimentos e, antes disso, políticas institucionais para dar suporte às práticas documentárias. Do contrário, continuarão sendo, em sua maioria, apenas espaços de guarda de bens culturais, descaracterizados de suas funções de produção e de disseminação de conhecimento (Lourenço, 1999). A adoção de um esquema de metadados, portanto, só poderá ser bem-sucedida e trazer benefícios se políticas e estratégias basilares estiverem bem definidas e alinhadas. Ademais, conforme advertiram Olcina (1986) e Baca (2016b), qualquer implantação de práticas é realizada de modo gradual. 


\section{Cotejo das diretrizes e análise dos formatos de descrição recomendados}

Para construir um esquema de metadados mínimos para a descrição de acervos museológicos, voltado às coleções de arte no Brasil e fundamentado em diretrizes consolidadas e atualizadas, foram adotados os procedimentos metodológicos descritos no Quadro 1, executados em três fases.

Quadro 1 - Fases do trabalho de mapeamento de diretrizes para obras de arte (2019).

\begin{tabular}{llc}
\hline Fases & & Recursos utilizados \\
\hline 1 & Reconhecimento dos metadados: domínios das Artes Visuais e da Museologia & Lista de metadados \\
2 & Seleção dos metadados e correspondência entre os termos & Definição dos termos candidatos \\
3 & Coleta de dados dos termos: contextos, sinônimos e fontes & Ficha de coleta individual \\
3.1 & Análise das definições & Ficha de síntese individual \\
3.2 & Identificação das características em comum & Definições desmembradas em características \\
3.3 & Redação das sínteses definicionais & Formulação das definições \\
3.4 & Correspondência entre os conceitos: representação gráfica do mapeamento & Crosswalk \\
\hline
\end{tabular}

Fonte: Elaboração própria com base em Barros (2004), na norma no 25964-1/2 (International Organization for Standardization, 2011a; 201 1b), em Woodley (2016) e em Krieger e Finatto (2018).

O cotejo das diretrizes selecionadas - a SPECTRUM, a do CIDOC-ICOM e a CDWA -, para a análise e para a identificação de semelhanças e de diferenças entre os seus componentes (os metadados), foi realizado a partir de mapeamento, de crosswalk e de fichas de coleta e de síntese terminológicas. O mapeamento e o crosswalk foram pautados na norma documentária ISO 25964-1/2,"Information and documentation: thesauri and interoperability with other vocabularies" (International Organization for Standardization, 2011a; 2011b), e em Woodley (2016). A coleta terminológica foi amparada na metodologia de Terminologia apresentada por Barros (2004) e por Krieger e Finatto (2018) e permitiu a redação de sínteses definicionais de cada componente, classificados aqui como Subunidades de informação, Unidades de informação e Grupos de informação e designados por um termo candidato.

O mapeamento é o trabalho intelectual de cotejo entre esquemas de metadados, e o seu resultado representado graficamente é denominado crosswalk (International Organization for Standardization, 2011b; Woodley, 2016); os dois recursos facilitaram a visualização dos elementos a serem comparados. Já a coleta terminológica é a recolha e a análise de termos e de conceitos, apoiadas em fichas de coleta e de síntese. Os recursos terminológicos permitiram a identificação dos termos, sua sinonímia, os contextos de uso, o desmembramento e a comparação das características de cada metadado para melhor observação de suas propriedades em comum. Esse processo metodológico permitiu a escolha da designação a ser utilizada, a síntese das características comuns entre os termos e conceitos e a elaboração da definição de cada metadado selecionado. Uma vez estabelecido o conjunto de metadados e conhecidas suas características, foi possível, também, organizá-los em uma estrutura lógica e agrupá-los em Grupos de Informação. Essa organização evidencia as relações mútuas entre os metadados, o que permite um melhor uso do esquema pelos documentalistas (Silva; Lara, 2019; Silva, 2020).

A proposta de esquema mínimo de metadados elaborada atende a requisitos necessários para que o instrumento de catalogação seja interoperável, pois foi construído apoiando-se na semelhança estrutural das diretrizes em foco. Assim sendo, os metadados seguem padrões que permitem, por exemplo, a compatibilização com recursos mais avançados como o Linked Open Data. Em outras palavras, a descrição padronizada de dados em nível básico atende a requisitos exigidos para futuras aplicações em ambientes digitais e para a interoperabilidade, de acordo com protocolos como o Conceptual Reference Model do CIDOC-ICOM. Iniciativas mais recentes para aplicações digitais desse tipo estão em andamento pela comunidade denominada Linked Art (Linked Art, 2020). 
O Quadro 2 exibe a síntese do mapeamento realizado com os metadados selecionados das três diretrizes, com a indicação das equivalências exata, parcial e inexata da norma ISO 25964-2 (International Organization for Standardization, 2011b), adaptadas para esta pesquisa. Assim, foram utilizadas as denominações 'idêntico', para sinalizar metadados com equivalência exata; 'análogo', para equivalência parcial; e 'exclusivo' e 'não consta', para equivalência inexata, isto é, para um metadado existente em uma diretriz, mas sem metadados correlatos nas demais, do ponto de vista conceitual.

Quadro 2 - Síntese do mapeamento dos metadados das diretrizes selecionadas (2020).

\begin{tabular}{lll}
\hline Termo Candidato & SPECTRUM CIDOC-ICOM & CDWA \\
\hline Objeto & ¿
\end{tabular}

Nível de catalogação

Tipo de objeto/obra

\section{Classificação}

Termo de classificação

\section{Título do objeto}

Título

\section{Criação do objeto}

Descrição do criador

Identidade do criador

Função do criador

Data de criação

Data mais antiga

Data mais recente

\section{Medidas}

Descrição das dimensões

Tipo das dimensões

Valor das dimensões

Unidade de medida

Parte medida

\section{Materiais/técnicas}

Descrição de materiais/técnicas

Nomes dos materiais/técnicas

\section{Assunto representado}

Termos do assunto geral

\section{Localização}

Localização atual

Localização usual

Tipo de localização

Número do objeto

Tipo de número do objeto

\section{Referências relacionadas}

Referências

Tipo da referência 


\section{Proposta de esquema básico de metadados para representação descritiva de obras de arte em museus do Brasil}

O mapeamento das três diretrizes gerou um conjunto selecionado de Unidades de informação consideradas essenciais para o registro catalográfico, relacionadas entre si e distribuídas em Grupos de informação, os quais têm a função de agrupar metadados da mesma natureza, não constituindo, portanto, campos a serem preenchidos. Já cada Unidade de informação equivale a um metadado e seu preenchimento é obrigatório, seja com o uso de vocabulários controlados (tesauros, listas controladas, autoridades de pessoa/organização e de localização) ou com texto-livre, de acordo com as recomendações adotadas pelo museu. Algumas Unidades de informação possuem Subunidades de informação que servem para fornecer detalhes sobre os dados.

O esquema básico de metadados proposto pode ser adaptado às especificidades e às necessidades de cada museu, sendo, portanto, apenas um modelo de referência. No Quadro 3, são apresentados os componentes da proposta acompanhados de suas sínteses definicionais que, além da definição, podem incluir exemplos e orientações elementares que elucidam seu uso. Os metadados estão organizados em uma estrutura lógica, conforme se observa na primeira coluna. Atenção deve ser dada à numeração progressiva, colocada à esquerda do quadro, quando da inserção de um novo metadado, pois ela indicará sua posição na estrutura hierárquica.

A Unidade de informação 'Termos do assunto geral' do Grupo de informação no 7 merece destaque, pois, conforme afirma Harpring (2019), fundamentada em investigação realizada pela Online Computer Library Center, essa é, em geral, a informação essencial menos utilizada por museus de arte. Como consequência, as obras não são processadas de modo a serem recuperadas pelos assuntos nelas representados, os quais podem, segundo a autora, ser de três níveis: descrição, identificação e interpretação. No primeiro nível, registram-se termos que descrevem o que pode ser visto na obra, por exemplo, 'cavalo'; no segundo nível, termos relativos às pessoas ou eventos identificados, como 'São Tiago'; e, no último nível, termos relacionados ao que pode ser interpretado na obra, como 'poder' (Harpring, 2019). Embora a recomendação para um registro básico seja preencher termos gerais para assunto, pode-se registrar também termos específicos para ampliar a possibilidade de recuperação de informações.

O desenho de um esquema básico de metadados elaborado a partir das três diretrizes selecionadas resultou do estabelecimento e do cumprimento dos seguintes critérios: (a) destinado a obras de arte; (b) composto por elementos mínimos que permitem distinguir um objeto do outro dentro de uma coleção, ao mesmo tempo que viabilizam a identificação e a localização de cada objeto do acervo; (c) sustentado em diretrizes atualizadas e reconhecidas internacionalmente e (d) adaptado aos contextos locais, isto é, considerando a falta de recursos de diversas naturezas (tempo, pessoal, material, financeiro). O esquema proposto é um recurso metodológico flexível, podendo ser usado de imediato, resguardadas as especificidades de cada coleção de arte e os objetivos de cada museu para a representação informacional de seus bens culturais. Sua construção buscou incluir as principais contribuições de cada uma das três diretrizes analisadas dentro dos objetivos da pesquisa e dos critérios expostos. O passo seguinte, após o desenho desse esquema, foi testar a sua aplicação em uma amostra de obras de arte pertencentes aos museus do Brasil.

\section{Aplicação da proposta em uma amostra de obras de arte de museus brasileiros}

Para se verificar a aplicabilidade da proposta do esquema básico de metadados, procedeu-se à seleção de obras de Artes Visuais presentes em museus do Brasil. Na seleção, buscou-se contemplar obras de arte de categorias diferentes a partir de um levantamento feito previamente nos sites institucionais de 99 museus de arte, em seus perfis em redes sociais ou nos sites das prefeituras responsáveis pelos equipamentos culturais. Ainda, foram privilegiadas obras com informações online publicadas sobre elas e seus criadores em fontes confiáveis, sobretudo 
Quadro 3 - Proposta de esquema básico de metadados para obras de arte em museus brasileiros (2020).

\begin{tabular}{|c|c|c|}
\hline No & Componente & Síntese definicional \\
\hline$\overline{1}$ & $\begin{array}{l}\text { Grupo de informação } \\
\text { Objeto }\end{array}$ & $\begin{array}{l}\text { Identificação do tipo e do número do objeto descrito. Esse Grupo de informação descreve o } \\
\text { que é o objeto e possibilita a busca, em um sistema, por objetos de um determinado tipo e seus } \\
\text { componentes. }\end{array}$ \\
\hline 1.1 & $\begin{array}{l}\text { Unidade de informação } \\
\text { Nível de catalogação }\end{array}$ & $\begin{array}{l}\text { Termo que indica se o registro representa um item, volume, grupo, subgrupo, coleção, série, conjunto } \\
\text { ou componente. }\end{array}$ \\
\hline 1.2 & $\begin{array}{l}\text { Unidade de informação } \\
\text { Tipo de objeto/obra }\end{array}$ & $\begin{array}{l}\text { Termo que indica o tipo de obra de arte ou o grupo de obras descritos no registro. } \\
\text { Exemplos: álbum, caderno de desenho, colar, desenho, estátua, fotografia, gravura, instalação, } \\
\text { moeda, performance, pintura, vídeo. } \\
\text { Orientação: recomenda-se usar o termo mais específico e apropriado. O foco da coleção e a expertise } \\
\text { dos usuários devem ser considerados na escolha dos termos, incluindo tanto o usuário especialista } \\
\text { como o usuário geral. Uma obra pode ser uma única coisa física, um fragmento, uma obra composta } \\
\text { de muitas partes ou um evento considerado uma obra de arte. }\end{array}$ \\
\hline 2 & $\begin{array}{l}\text { Grupo de informação } \\
\text { Classificação }\end{array}$ & $\begin{array}{l}\text { Posição de uma obra de arte dentro de um esquema de classificação que agrupa outras obras } \\
\text { semelhantes com base em suas características. Um esquema de classificação pode ser uma } \\
\text { hierarquia, tipologia ou agrupamento informal. Muitas vezes, objetos que não possuem títulos são } \\
\text { conhecidos pelos seus Termos de classificação ou Tipos de objeto/obra. }\end{array}$ \\
\hline- & $\begin{array}{l}\text { Unidade de informação } \\
\text { Termo de classificação }\end{array}$ & $\begin{array}{l}\text { Termo de um esquema de classificação atribuído a um objeto (por exemplo, escultura, móveis, } \\
\text { pintura, artes gráficas). } \\
\text { Orientação: registre termos que relacionam o objeto a outros objetos com características } \\
\text { semelhantes, incluindo materiais, forma, função, região de origem, contexto cultural ou período } \\
\text { histórico ou estilístico. É possível registrar vários termos em relação a um objeto, para indicar suas } \\
\text { diversas características. Os termos de classificação são extraídos de sistemas ordenados de categorias } \\
\text { ou de tesauros hierarquicamente estruturados. }\end{array}$ \\
\hline 3 & $\begin{array}{l}\text { Grupo de informação } \\
\text { Título do objeto }\end{array}$ & $\begin{array}{l}\text { Títulos ou nomes dados a um objeto de arte. O título ou nome é frequentemente a principal } \\
\text { identificação do objeto de arte. Um objeto pode ter mais de um título, podendo sofrer alterações } \\
\text { ao longo do tempo. }\end{array}$ \\
\hline- & $\begin{array}{l}\text { Unidade de informação } \\
\text { Título }\end{array}$ & $\begin{array}{l}\text { Títulos, frases de identificação ou nomes atribuídos a um objeto ou grupo de objetos pelo artista/ } \\
\text { criador ou coletor na sua origem, ou títulos subsequentes. } \\
\text { Orientação: títulos devem ser, em geral, concisos e específicos para o objeto. Um objeto pode ser } \\
\text { conhecido por múltiplos títulos ou nomes, registre-os nesta Unidade de informação. }\end{array}$ \\
\hline 4 & $\begin{array}{l}\text { Grupo de informação } \\
\text { Criação do objeto }\end{array}$ & $\begin{array}{l}\text { Informações relativas à produção, criação, projeto ou execução de um objeto e seus componentes. } \\
\text { Inclui, ainda, o registro dos responsáveis pela criação do objeto ou dos itens em um grupo e das } \\
\text { datas de criação do objeto. }\end{array}$ \\
\hline 4.1 & $\begin{array}{l}\text { Unidade de informação } \\
\text { Descrição do criador* }\end{array}$ & $\begin{array}{l}\text { Nome, informações biográficas breves e funções dos indivíduos anônimos ou nomeados ou das } \\
\text { corporações responsáveis pelo design, produção, fabricação ou alteração do objeto. }\end{array}$ \\
\hline 4.1 .1 & $\begin{array}{l}\text { Subunidade de informação } \\
\text { Identidade do criador }\end{array}$ & $\begin{array}{l}\text { Identidade de qualquer indivíduo ou organização que tenha desempenhado um papel na criação } \\
\text { de uma obra de arte. }\end{array}$ \\
\hline 4.1.2 & $\begin{array}{l}\text { Subunidade de informação } \\
\text { Função do criador }\end{array}$ & $\begin{array}{l}\text { Função ou atividade desempenhada por um criador na concepção, no projeto ou na produção de } \\
\text { um objeto. } \\
\text { Exemplos: artista, editor, escritório de arquitetura, escultor, desenhista, designer, gravador, muralista, } \\
\text { oleiro, ourives, pintor. } \\
\text { Orientação: Registre o papel mais específico do criador, se conhecido. }\end{array}$ \\
\hline 4.2 & $\begin{array}{l}\text { Unidade de informação } \\
\text { Data de criação }\end{array}$ & $\begin{array}{l}\text { Data ou intervalo de datas associadas à produção, concepção, criação, apresentação ou alteração do } \\
\text { objeto ou de seus componentes. } \\
\text { Orientação: seja o mais preciso possível ao registrar datas. Valores para a data devem ser fornecidos } \\
\text { mesmo quando a informação é incerta. Nesse caso, deve ser feita consulta às diretrizes para conferir } \\
\text { o modo de registro. Se a data de criação for desconhecida, uma data estimada pode ser fornecida. }\end{array}$ \\
\hline 4.2 .1 & $\begin{array}{l}\text { Subunidade de informação } \\
\text { Data mais antiga }\end{array}$ & $\begin{array}{l}\text { Data mais próxima possível de quando a obra de arte foi criada. Para objetos que foram criados ao } \\
\text { longo de um período de tempo, este é o ano em que o objeto foi projetado ou quando a execução } \\
\text { foi iniciada. Para datas incertas ou aproximadas, este é o ano mais antigo possível em que o objeto } \\
\text { pode ter sido iniciado ou projetado. } \\
\text { Orientação: seja tão especíico quanto possível no registro. }\end{array}$ \\
\hline 4.2 .2 & $\begin{array}{l}\text { Subunidade de informação } \\
\text { Data mais recente }\end{array}$ & $\begin{array}{l}\text { Data mais recente possível em que a obra de arte foi criada. Para obras que foram criadas ao longo } \\
\text { de um período de tempo, trata-se do ano em que o objeto foi concluído ou quando a estrutura } \\
\text { foi realizada. Para datas incertas ou aproximadas, é o ano mais recente possível em que o trabalho } \\
\text { poderia ter sido concluído. } \\
\text { Orientação: seja tão específico quanto possível no registro. }\end{array}$ \\
\hline
\end{tabular}


Quadro 3 - Proposta de esquema básico de metadados para obras de arte em museus brasileiros (2020).

\begin{tabular}{|c|c|c|}
\hline No & Componente & Síntese definicional \\
\hline 5 & $\begin{array}{l}\text { Grupo de informação } \\
\text { Medidas }\end{array}$ & $\begin{array}{l}\text { Informações sobre o tamanho, forma, escala e dimensões de uma obra de arte. Um objeto que é } \\
\text { considerado basicamente bidimensional, como uma pintura, geralmente é medido em altura e } \\
\text { largura. Trabalhos destinados a serem vistos em três dimensões são normalmente medidos em altura, } \\
\text { largura e profundidade. Peso, tamanho e formato podem ser importantes. Para um vídeo ou filme, } \\
\text { o formato técnico e o tempo de duração são a forma habitual de identificação da obra. A avaliação } \\
\text { de tamanho, forma e formato pode exigir um conhecimento especializado das características de um } \\
\text { meio específico. }\end{array}$ \\
\hline 5.1 & $\begin{array}{l}\text { Unidade de informação } \\
\text { Descrição das dimensões* }\end{array}$ & $\begin{array}{l}\text { Informações sobre as dimensões, tamanho ou escala do objeto, de uma parte do objeto ou de seus } \\
\text { componentes. Além das dimensões regulares (altura, largura e profundidade), pode incluir a descrição } \\
\text { de: formas incomuns, escala, dimensões irregulares, medidas de várias partes, trabalhos sobre papel, } \\
\text { manuscritos, livros, dimensões aproximadas, medições de observação, medições históricas, peso, } \\
\text { formato, tempo de execução/duração, tamanho, novas mídias e grupo ou coleção de obras. }\end{array}$ \\
\hline 5.2 & $\begin{array}{l}\text { Unidade de informação } \\
\text { Tipo das dimensões }\end{array}$ & $\begin{array}{l}\text { Tipo de dimensão do objeto, de uma parte ou componente de um objeto a ser medido. } \\
\text { Exemplos: altura, largura, profundidade, comprimento, circunferência, diâmetro, raio, volume, peso, } \\
\text { alvo, área, base, contagem, tempo de execução. }\end{array}$ \\
\hline 5.3 & $\begin{array}{l}\text { Unidade de informação } \\
\text { Valor das dimensões }\end{array}$ & $\begin{array}{l}\text { Valor numérico da medida de um objeto ou parte do objeto. O valor deve ser tão preciso quanto } \\
\text { exige a tipologia do objeto e as necessidades do procedimento e da instituição. } \\
\text { Orientação: registre apenas uma vez para cada dimensão. }\end{array}$ \\
\hline 5.4 & $\begin{array}{l}\text { Unidade de informação } \\
\text { Unidade de medida }\end{array}$ & $\begin{array}{l}\text { Unidade de medida usada quando se mede um objeto ou parte de um objeto. } \\
\text { Exemplos: milímetros, centímetros, metros, centímetros cúbicos, litros, minutos, quilates, quilogramas, } \\
\text { pixels, polegadas. }\end{array}$ \\
\hline 5.5 & $\begin{array}{l}\text { Unidade de informação } \\
\text { Parte medida }\end{array}$ & $\begin{array}{l}\text { Parte do objeto que está sendo mensurada. } \\
\text { Exemplos: área da bandeja (excluindo a moldura), base, componentes, diâmetro, esteira, folha, } \\
\text { imagem, inteiro, marca de chapa, moldura, montagem, padrão, pegada, repetição, suporte } \\
\text { secundário, tampa. }\end{array}$ \\
\hline 6 & $\begin{array}{l}\text { Grupo de informação } \\
\text { Materiais/técnicas }\end{array}$ & $\begin{array}{l}\text { Substâncias ou materiais utilizados na criação de uma obra de arte, bem como quaisquer técnicas de } \\
\text { produção e processos ou métodos incorporados em sua fabricação. Essas informações incluem uma } \\
\text { descrição dos materiais usados para criar o trabalho e a maneira como eles foram utilizados. }\end{array}$ \\
\hline 6.1 & $\begin{array}{l}\text { Unidade de informação } \\
\text { Descrição de materiais/ } \\
\text { técnicas* }\end{array}$ & $\begin{array}{l}\text { Substâncias ou materiais utilizados na criação de uma obra, bem como quaisquer implementos, } \\
\text { técnicas, processos ou métodos incorporados em sua produção. }\end{array}$ \\
\hline 6.2 & $\begin{array}{l}\text { Unidade de informação } \\
\text { Nomes dos materiais/ } \\
\text { técnicas }\end{array}$ & $\begin{array}{l}\text { Nomes do material ou substância usada para criar a obra de arte; nomes dos meios, métodos, } \\
\text { processos ou técnicas usadas na criação de um trabalho; ou o nome de qualquer implemento ou } \\
\text { ferramenta usada para criar o trabalho usando o processo ou a técnica. } \\
\text { Exemplos: } \\
\text { a) materiais: carvão, madeira, mármore, papel, verniz, vidro; } \\
\text { b) técnicas/implementos: desenho, entalhe, escultura, gravura, pintura, tecelagem. } \\
\text { Orientação: registre os termos mais específicos. Esta Unidade de informação poderá ser repetida. }\end{array}$ \\
\hline 7 & $\begin{array}{l}\text { Grupo de informação } \\
\text { Assunto representado }\end{array}$ & $\begin{array}{l}\text { Significado narrativo, iconográfico ou não objetivo transmitido por uma composição abstrata ou } \\
\text { figurativa. Também abrange a função de um objeto que não possui conteúdo narrativo. Esse Grupo } \\
\text { de informação pode incluir uma identificação, descrição e/ou interpretação do que é representado } \\
\text { em e por uma obra ou imagem. Pode incluir informações sobre pessoas, lugares, eventos ou objetos } \\
\text { representados. }\end{array}$ \\
\hline- & $\begin{array}{l}\text { Unidade de informação } \\
\text { Termos do assunto geral }\end{array}$ & $\begin{array}{l}\text { Termos de indexação que caracterizam o que o trabalho representa ou o que é representado nele. } \\
\text { Exemplos: animal, natureza morta, retrato, tema literário, vestuário. } \\
\text { Orientação: recomenda-se também listar assuntos especíicos, se possível. É necessário registrar o } \\
\text { assunto aqui, mesmo que o assunto seja mencionado nas Unidades de informação 'Tipo de objeto/ } \\
\text { obra' ou 'Título'. }\end{array}$ \\
\hline 8 & $\begin{array}{l}\text { Grupo de informação } \\
\text { Localização }\end{array}$ & $\begin{array}{l}\text { Nome e localização geográfica do repositório que atualmente é responsável pela obra. Se o trabalho } \\
\text { for perdido, destruído, for de local desconhecido ou estiver em uma coleção particular anônima, essa } \\
\text { condição deverá ser registrada. Também inclui o número do repositório. Este Grupo de informação } \\
\text { também pode conter informações sobre locais anteriores do trabalho. Registre a informação de } \\
\text { localização de todos os objetos sob a custódia do museu, incluindo objetos em empréstimo ou } \\
\text { depósito temporários. Se o objeto ou trabalho construído for perdido ou destruído, é importante } \\
\text { saber sua localização conhecida mais recente. }\end{array}$ \\
\hline
\end{tabular}


Quadro 3 - Proposta de esquema básico de metadados para obras de arte em museus brasileiros (2020).

\begin{tabular}{|c|c|c|}
\hline No & Componente & Síntese definicional \\
\hline 8.1 & $\begin{array}{l}\text { Unidade de informação } \\
\text { Localização atual }\end{array}$ & $\begin{array}{l}\text { Local onde um objeto está fisicamente localizado no momento atual. } \\
\text { Exemplos: } \\
\text { a) Repositórios (organização): Departamento de Gravuras e Desenhos (Metropolitan Museum of Art, } \\
\text { Nova York, Nova York, EUA); } \\
\text { b) Localização geográfica: Piazza dei Caprettari (Roma, Itália); } \\
\text { c) Localizações específicas: Galeria 223, Arte Asiática, segundo andar; Galeria } 56 \text { / Caixa } 2 \text { / Prateleira A. } \\
\text { Orientação: registre o nome do repositório (por exemplo, museu ou igreja) ou local geográfico } \\
\text { onde o trabalho está localizado atualmente ou foi localizado pela última vez. Se o trabalho não for } \\
\text { mais existente ou se o local for desconhecido, isso deve ser indicado. Para objetos emprestados a } \\
\text { outras instituições deverá haver uma indicação de que o objeto foi emprestado. A informação de } \\
\text { 'Localização atual' deve ser precisa e incluir, conforme o caso, os detalhes do edifício, sala, armário, } \\
\text { prateleira e caixa onde o objeto se encontra. A localização atual deve ser verificada periodicamente } \\
\text { para garantir que está correta. }\end{array}$ \\
\hline 8.2 & $\begin{array}{l}\text { Unidade de informação } \\
\text { Localização usual }\end{array}$ & $\begin{array}{l}\text { Local onde um objeto está normalmente localizado e para onde ele deverá retornar a partir da } \\
\text { localização atual, quando diferente. } \\
\text { Orientação: a informação sobre a localização usual deve ser precisa e incluir, conforme o caso, os } \\
\text { detalhes do edifício, sala, armário, prateleira e caixa onde o objeto normalmente se encontra. }\end{array}$ \\
\hline 8.3 & $\begin{array}{l}\text { Unidade de informação } \\
\text { Tipo de localização }\end{array}$ & $\begin{array}{l}\text { Natureza de uma localização. } \\
\text { Exemplos: coleção privada, criação, descoberta, destruído, exposição, indeterminado, laboratório de } \\
\text { conservação, original, perdido, publicação, reserva técnica, várias localidades. } \\
\text { Orientação: use esta Unidade de informação também para indicar obras perdidas ou destruídas, } \\
\text { obras que tenham vários locais, obras que estejam em coleções particulares sem nome, local de } \\
\text { publicação de obras impressas e outros tipos de locais. }\end{array}$ \\
\hline 8.4 & $\begin{array}{l}\text { Unidade de informação } \\
\text { Número do objeto }\end{array}$ & $\begin{array}{l}\text { Número de identificação único atribuído pela instituição para cada objeto. } \\
\text { Orientação: esse número também serve para relacionar um objeto à sua documentação. Para isso, } \\
\text { o número de objeto deverá ser escrito de forma legível ou impresso em todos os documentos } \\
\text { relacionados ao objeto, sendo anexado de forma semipermanente no próprio objeto ou - no caso de } \\
\text { objetos muito pequenos, ou que não permitam uma marcação semipermanente -, na embalagem } \\
\text { que envolve o objeto. Registre os vários números do objeto, se necessário. Por exemplo, quando } \\
\text { o número mudou ao longo do tempo ou quando um único objeto é composto de fragmentos } \\
\text { adquiridos no decorrer do tempo. }\end{array}$ \\
\hline 8.5 & $\begin{array}{l}\text { Unidade de informação } \\
\text { Tipo de número do objeto }\end{array}$ & $\begin{array}{l}\text { Tipo de número ou outro identificador único atribuído a um objeto pelo atual ou último repositório. } \\
\text { Exemplos: identificador do objeto, número de acesso, número de empréstimo anterior, número de } \\
\text { inventário, número de prateleira. } \\
\text { Orientação: registre um termo descrevendo o tipo de número, se conhecido. }\end{array}$ \\
\hline 9 & $\begin{array}{l}\text { Grupo de informação } \\
\text { Referências relacionadas }\end{array}$ & $\begin{array}{l}\text { Citações de fontes de informação textual relacionadas à obra de arte descrita, incluindo materiais } \\
\text { bibliográficos publicados, sites da web, documentos de arquivo, manuscritos não publicados e } \\
\text { referências a opiniões verbais expressas por estudiosos ou especialistas. As referências estabelecem a } \\
\text { credibilidade da informação. É altamente recomendável registrar as fontes usadas no preenchimento } \\
\text { dos campos sobre a obra. }\end{array}$ \\
\hline 9.1 & $\begin{array}{l}\text { Unidade de informação } \\
\text { Referências }\end{array}$ & $\begin{array}{l}\text { Detalhes de uma referência bibliográfica ou outra referência associada a um objeto. } \\
\text { Orientação: a referência pode estar em qualquer suporte, por exemplo, publicada, não publicada, } \\
\text { áudio, registro digital, vídeo. }\end{array}$ \\
\hline 9.2 & $\begin{array}{l}\text { Unidade de informação } \\
\text { Tipo da referência }\end{array}$ & $\begin{array}{l}\text { Termo que descreve a natureza da referência. } \\
\text { Exemplos: artigo de jornal, artigo de periódico, atlas, biografia, carta, catálogo de exposições, crítica, } \\
\text { dicionário, dissertação, filme, folheto, contrato, guia de viagem, inventário, monografia, opinião } \\
\text { verbal, relatório de condição, site. } \\
\text { Orientação: classifique o documento pelo tipo. }\end{array}$ \\
\hline
\end{tabular}

Fonte: Elaborado pelos autores a partir dos dados das diretrizes SPECTRUM (Collections Trust, 2014), CIDOC-ICOM (2014) e CDWA (Getty Research Institute, 2019).

Nota: "Metadado opcional destinado ao uso em ambientes virtuais. De modo geral, ele sintetiza as informações dos metadados pertencentes ao mesmo Grupo de informação; - Metadado sem numeração. Nesta proposta, é o elemento único de um Grupo de informação. 
em catálogos de suas respectivas instituições. A opção por esse levantamento visou contornar a impossibilidade de observação direta, bem como a consulta aos documentos de aquisição e aos dossiês. Exceção foi feita aos dossiês e às fichas catalográficas das obras selecionadas pertencentes ao Museu de Arte Contemporânea da Universidade de São Paulo e ao Museu de Arte de São Paulo Assis Chateaubriand.

A observar que nem sempre um museu dispõe de informações suficientes para o preenchimento do registro catalográfico da obra, o que implica que elas precisarão ser produzidas. Geralmente, parte das informações sobre uma obra estão presentes em seus documentos de entrada, como termos de doação e compra. A guarda, a manutenção e a preservação desses documentos têm que estar previstas na política de aquisição da instituição, de forma a garantir o registro de obras. Outras informações poderão ser recuperadas de fontes como catálogos de exposição, trabalhos acadêmicos, correspondências com o artista (cartas, e-mails, bilhetes), matérias de jornais e revistas que, em geral, compõem o dossiê da obra. Informações sobre medidas, por exemplo, precisarão ser produzidas pela instituição a partir de parâmetros de medição pré-definidos (Young, 2010; Panisset, 2017b). Caso as obras do acervo não possuam um número de identificação, este deverá ser atribuído de acordo com um formato de numeração adotado (ou a ser adotado) pelo museu (Buck, 2010).

Foram selecionadas treze obras das seguintes categorias: arte digital (mídias contemporâneas), arte postal (arte conceitual), cerâmica (artes decorativas), escultura (arte moderna), escultura (arte popular), fotografia, gravura (arte popular), imaginária (arte sacra), instalação (mídias contemporâneas), livro de artista, mobiliário, tapeçaria e vestuário. Essas obras pertencem a museus dos estados da Bahia, Paraná, Pernambuco, Rio de Janeiro, Rio Grande do Sul, Santa Catarina e São Paulo, em uma tentativa de incorporar objetos localizados em diferentes regiões do país. Em seguida, foram feitos seus registros, com a aplicação do modelo de metadados proposto e obedecendose às recomendações de padrões de valores (como vocabulários controlados) e de conteúdo de dados (regras de catalogação).

Foi possível verificar a aplicabilidade da proposta a partir da amostra escolhida e observar a necessidade de inserção de novos metadados quando necessário, a depender das singularidades de cada obra de arte. Para obras do tipo 'instalação', por exemplo, o metadado referente à montagem poderá ser fundamental. A experiência permitiu reunir informações para uma futura expansão da amostra, de modo a incluir diferentes atributos não observados e não avaliados.

O esquema proposto mostrou-se um produto simples, pois o preenchimento dos metadados foi realizado sem maiores dificuldades. Apesar de nenhum sistema de organização do conhecimento ser estável e universal, conforme apontam Lara (2013) e Baca (2016b), acredita-se que esse esquema poderá ser utilizado por aqueles museus do Brasil que carecem de orientações metodológicas para o registro catalográfico de suas coleções de arte, seja em sistemas manuais ou informatizados.

Os sistemas de organização do conhecimento não são neutros, bem como não respondem universalmente a todos os propósitos: o recorte de um domínio e a estruturação de seus conceitos definem seus limites de aplicação. Assim como as formas de organização são múltiplas, vários são também os públicos da informação e nenhum vocabulário, por melhor que esteja organizado, é adequado a todos os contextos ou situações (Lara, 2013, p.149, tradução nossa) ${ }^{\mathbf{3}}$.

No trecho apresentado, Lara (2013) refere-se aos vocabulários controlados, mas o argumento vale também para os esquemas de metadados. Do mesmo modo, Baca (2016b, online), no princípio no 6, dentre os dez que ela enumerou para a criação e manutenção de metadados, afirma que "não existe um único esquema de metadados

\footnotetext{
${ }^{3}$ No original: "Knowledge organization systems are not neutral and do not respond to all purposes universally: the delimitation of a domain structure and the structuring of their concepts define their limits of application. As there are various forms of organization there is always a target audience for the information, and no vocabulary, as well-organized as it may be, is appropriate for all existing contexts and situations" (Lara, 2013, p.149).
} 
ou vocabulário controlado ou padrão de conteúdo de dados (catalogação) 'que sirva para todos"' os equipamentos culturais. Ela completa:

As instituições devem escolher cuidadosamente o conjunto apropriado de esquemas de metadados e vocabulários controlados (incluindo tesauros específicos para a coleção e listas locais de opções), juntamente com os padrões de catalogação mais apropriados (incluindo diretrizes de catalogação locais baseadas em padrões publicados) para melhor descrever e fornecer acesso às suas coleções e outros recursos (Baca, 2016b, online, tradução nossa) ${ }^{4}$.

Uma opção para a aplicação da presente proposta em ambiente digital é a plataforma Tainacan, programa gratuito distribuído pelo IBRAM. Por se tratar de um instrumento de registro (um suporte), o museu necessariamente deverá definir um esquema de metadados a ser implantando (Tainacan, 2019). Uma vez definido, seus componentes precisarão ser incluídos na plataforma pelo documentalista do museu, formando, assim, a combinação ideal entre o suporte (o Tainacan, no caso) e as recomendações metodológicas específicas para objetos museológicos (o esquema de metadados), para tonar possível o registro descritivo, com atenção às tipologias.

\section{Considerações Finais}

A pesquisa efetuada permite confirmar que o desenho de um esquema básico de metadados para obras de Artes Visuais, pautado em diretrizes consolidadas e atualizadas, pode ser aplicável e útil aos museus brasileiros que enfrentam a falta de recursos de diversas naturezas. O uso de um instrumento documentário simples para o registro de dados mínimos sobre as obras de suas coleções é passível de ajustes às necessidades informacionais específicas de cada instituição. Nada impede que esses registros sejam, depois, enriquecidos com a inclusão de novos metadados ou com a atualização dos dados existentes.

Mesmo considerando que nenhum sistema de organização servirá para as necessidades de todas as instituições, o uso de um esquema básico de metadados poderá contribuir para promover boas práticas e estimular críticas para o seu aperfeiçoamento. Mais importante, um sistema de informações organizado propiciará a otimização do acesso informacional às obras de arte nos museus brasileiros e poderá intensificar a extroversão dos acervos e criar condições para a produção do conhecimento sobre as obras de arte, uma vez que o conjunto de informações registrado constitui fonte de pesquisa importante. A atualização das informações nos registros a partir da produção de conhecimento sobre as obras também contribuirá para elevar o nível de granularidade dos dados registrados e, consequentemente, possibilitar maior recuperação. Por último, a implantação de um esquema básico de metadados preparará os dados para a interoperabilidade, como o Linked Open Data, à medida que já estarão processados e estruturados.

Espera-se que o resultado deste trabalho seja um meio para enfatizar a potencialidade do diálogo entre as áreas da Ciência da informação e da Museologia, no sentido de ampliar as discussões em torno da documentação em museus. Do mesmo modo, que possa ser útil para o desenvolvimento de outras propostas de padrões de estrutura de dados, visando estender a oferta de instrumentos documentários para os museus nacionais com diferentes tipologias de acervo.

Ao mesmo tempo, há a expectativa de que as políticas institucionais de gestão de coleções museológicas contemplem procedimentos de catalogação para os acervos, pois a aplicação de esquemas de metadados só fará sentido se alinhada à missão e aos objetivos do museu. Em um cenário ideal, a adoção de padrões e de diretrizes com uma estrutura básica semelhante pela comunidade de museus responsáveis por coleções de arte será fortalecida

\footnotetext{
${ }^{4}$ No original: "Institutions must carefully choose the appropriate suite of metadata schemas and controlled vocabularies (including collection-specific thesauri and local pick lists), along with the most appropriate cataloging standards (including local cataloging guidelines based on published standards) to best describe and provide access to their collections and other resources" (Baca, 2016b, online).
} 
com a produção de dados intercambiáveis e interoperáveis, o que significa maior grau de compartilhamento de informações.

Para finalizar, a amostra utilizada para testar o modelo proposto será expandida em trabalhos futuros para identificar situações não previstas, em vista das singularidades de cada obra de arte. Além disso, enfatiza-se a importância de contemplar a análise dos outros tipos de padrões de dados básicos, principalmente relacionados ao preenchimento de metadados relativos a vocabulários para representação temática.

\section{Colaboradores}

Ambas as autoras participaram da concepção, análise dos dados, redação e revisão do artigo.

\section{Referências}

Baca, M. Introduction. In: Baca, M. (ed.). Introduction to metadata. 3rd ed. Los Angeles: Getty Research Institute, 2016a. Versão online. Available from: https://www.getty.edu/ publications/intrometadata/introduction/. Cited: May 8, 2020.

Baca, M. Practical principles for metadata creation and maintenance. In: Baca, M. (ed.). Introduction to metadata. 3rd ed. Los Angeles: Getty Research Institute, 2016b. Versão online. Available from: http://www.getty.edu/publications/ intrometadata/practical-principles/. Cited: May 8, 2020.

Barros, L. A. Curso básico de terminologia. São Paulo: EDUSP, 2004.

Barroso, G. Introdução à técnica de museus. Rio de Janeiro: Gráfica Olimpica, 1946.

British Standards Institution. PAS 197: 2009 - Code of practice for cultural collections management. London: British Standards Institution, 2009.

Buck, R. A. Numbering. In: Buck, R. A.; Gilmore, J. A. (ed.). Museum registration methods. 5th ed. Washington: American Association of Museums, 2010. p. 206-208.

Camargo-Moro, F. Museus, aquisição/documentação: tecnologias apropriadas para a preservação dos bens culturais. Rio de Janeiro: Livraria Eça, 1986.

CIDOC-ICOM. International guidelines for museum object information: the CIDOC Information Categories. Paris: International Committee for Documentation of the International Council of Museums, 1995. Available from: http://network.icom.museum/fileadmin/user_upload/ minisites/cidoc/DocStandards/guidelines1995.pdf. Cited: May 29, 2020.

CIDOC-ICOM. Statement of principles of museum documentation. [S. I.]: CIDOC Documentation Standards Working Group, 2012. Version 6.2. Available from: http://cidoc. mini.icom.museum/wp-content/uploads/sites/6/2020/03/ principles6_2.pdf. Cited: May 29, 2020.

CIDOC-ICOM. Declaração de princípios de documentação em museus e Diretrizes internacionais de informação sobre objetos de museus: categorias de Informação do Comitê Internacional de Documentação (CIDOC - ICOM). São Paulo: Secretaria de Estado da Cultura de São Paulo, 2014. Disponível em: https://issuu.com/sisem-sp/docs/cidoc_guidelines. Acesso em: 22 maio 2020.

Collections Trust. Spectrum 4.0: the UK museum documentation standard. 4th ed. [London]: Collections Trust, 2011. Available from: https://collectionstrust.org.uk/resource/ the-spectrum-standard-v4-0/. Cited: May 22, 2020.

Collections Trust. Spectrum 4.0: padrão para gestão de coleções de museus do Reino Unido. São Paulo: Secretaria de Estado da Cultura, 2014. Disponível em: https://issuu.com/ sisem-sp/docs/spectrum_pt_net. Acesso em: 22 maio 2020.

Collections Trust. Spectrum 5.0: the UK Museum collections management standard. [London]: Collections Trust, 2017. Available from: https://collectionstrust.org.uk/spectrum/ spectrum-5/. Cited: May 18, 2020.

Ferrez, H. D.; Peixoto, M. E. S. Manual de catalogação de pinturas, esculturas, desenhos e gravuras. Rio de Janeiro: Museu Nacional de Belas Artes, 1995.

Getty Research Institute. Categories for the description of works of art. Los Angeles: Getty Research Institute, 2019. Available from: https://www.getty.edu/research/publications/electronic_ publications/cdwa. Cited: May 8, 2020.

Gilliland, A. J. Setting the stage. In: Baca, M. (ed.). Introduction to metadata. 3rd ed. Los Angeles: Getty Research Institute, 2016. Versão online. Available from: https://www.getty.edu/ publications/intrometadata/setting-the-stage/. Cited: May 4, 2020.

Harpring, P. CONA and subject access for art works: overview of the CONA Depicted Subject. Los Angeles: Getty Research Institute, 2019. 144 p. Available from: https://www.getty.edu/ research/tools/vocabularies/cona_and_subject_access.pdf. Cited: May 28, 2020.

Instituto Brasileiro de Museus. Cadastro Nacional de Museus. Brasília: IBRAM, 2010.

Instituto Brasileiro de Museus. Museus em números. Brasília: Ministério da Cultura, 2011. v. 1. Disponível em: https://www. museus.gov.br/wp-content/uploads/2011/11/museus_em_ numeros_volume1.pdf. Acesso em: 17 abr. 2020.

International Organization for Standardization. ISO 259641: Information and documentation - thesauri and 
interoperability with other vocabularies. Part 1: Thesauri for information retrieval. Geneve: International Organization for Standardization, 2011a. 152 p.

International Organization for Standardization. ISO 25964-2: Information and documentation - thesauri and interoperability with other vocabularies. Part 2: Interoperability with other vocabularies. Geneve: International Organization for Standardization, 2011b. 105 p.

Krieger, M. G.; Finatto, M. J. B. Introdução à terminologia: teoria e prática. 2. ed. São Paulo: Contexto, 2018.

Lara, M. L. G. Documentary languages and knowledge organization systems in the context of the semantic web. Transinformação, v. 25, n. 2, p. 145-150, 2013. Doi: https://doi. org/10.1590/S0103-37862013000200005.

Linked Art. Editorial board: Robert Sanderson. [S. I.]: Linked Art, 2020. Available from: https://linked.art/. Cited: May 30, 2020.

Lourenço, M. C. F. Museus acolhem moderno. São Paulo: Edusp, 1999.

Monteiro, J. Documentação em museus e objeto-documento: sobre noções e práticas. 2014. 176 f. Dissertação (Mestrado em Ciência da Informação) - Escola de Comunicações e Artes da Universidade de São Paulo, São Paulo, 2014. Doi: https:// doi.org/10.11606/D.27.2014.tde-22012015-105632.

Olcina, P. The development and coordination of museum documentation by international agencies. In: Light, R. et al. (ed.). Museum Documentation Systems. London: Butterworths, 1986. p. 307-314.

Paaskoski, L. et al. Checklist para uma política de gestão de acervos. Pós: Revista do Programa de Pós-graduação em Artes da EBA/UFMG, v. 4, n. 8, p. 200-229, 2014. Disponível em: https://periodicos.ufmg.br/index.php/revistapos/article/ view/15490. Acesso em: 24 maio 2020.

Panisset, A. M. A documentação como ferramenta de preservação: protocolos para documentação e gestão do acervo artístico da UFMG. 2017a. v. 1, 397 f. Tese (Doutorado em Artes) - Escola de Belas Artes, Universidade Federal de Minas Gerais, Belo Horizonte, 2017a. Disponível em: http://hdl. handle.net/1843/LOMC-BC2GCX. Acesso em: 11 abr. 2020.

Panisset, A. M. A documentação como ferramenta de preservação: protocolos para documentação e gestão do acervo artístico da UFMG. 2017b. v. 2, 357 f. Tese (Doutorado em Artes) - Escola de Belas Artes, Universidade Federal de Minas Gerais, Belo Horizonte, 2017b. Disponível em: http://hdl. handle.net/1843/LOMC-BC2GCX. Acesso em: 11 abr. 2020.

Real, R. M. O museu ideal. Belo Horizonte: Tipografia da Faculdade de Direito da Universidade de Minas Gerais e do Centro Regional de Pesquisas Educacionais, 1958.

Secretaria de Estado da Cultura de São Paulo. Coleção gestão e documentação de acervos: textos de referência. São Paulo: Secretaria de Estado da Cultura de São Paulo, 2014. (Coleção gestão e documentação de acervos: textos de referência, v. 1-4). Disponível em: <https://issuu.com/sisem-sp/ stacks/512fa1bd6b9b420a8d077f95c54416e8>. Acesso em: 31 maio 2020.

Silva, C. A. Esquema de metadados para descrição de obras de arte em museus brasileiros: uma proposta. 2020. $646 \mathrm{f}$. Tese (Doutorado em Ciência da Informação) - Escola de Comunicações e Artes da Universidade de São Paulo, São Paulo, 2020.

Silva, C. A.; Lara, M. L. G. Metadados para descrição de acervos de arte no Brasil. In: ENANCIB, 20., 2019, Florianópolis. Anais eletrônico [...] Florianópolis: ENANCIB, 2019. Disponível em: https://conferencias.ufsc.br/index.php/enancib/2019/paper/ view/502. Acesso em: 19 abr. 2020.

Simmons, J. E. Collections management policies. In: Buck, R. A.; Gilmore, J. A. Museum Registration Methods. 5td ed. Washington: American Association of Museums, 2010. p. 23-29.

Tainacan. Usando o Tainacan: conceitos gerais. Coordenação Geral: Dalton Martins. Coordenador de desenvolvimento: Leonardo Germani. [S. I.: s. n.], 2019. 1 vídeo (14 min 23 seg). Publicado pelo canal Tainacan. Disponível em: https://youtu. be/fzbd36fbull. Acesso em: 20 abr. 2020.

Woodley, M. S. Metadata matters: connecting people and information. In: Baca, M. (ed.). Introduction to metadata. 3. ed. Los Angeles: Getty Research Institute, 2016. Versão online. Available from: https://www.getty.edu/publications/ intrometadata/metadata-matters/. Cited: May 4, 2020.

Young, H. Measuring. In: Buck, R. A.; Gilmore, J. A. (ed.). Museum Registration Methods. 5th ed. Washington: American Association of Museums, 2010. p. 219-222. 